\title{
Numerical development-from cognitive functions to neural underpinnings
}

\author{
Korbinian Moeller ${ }^{1,2 *}$, Elise Klein ${ }^{1,3}$, Karin Kucian ${ }^{4}$ and Klaus Willmes ${ }^{3}$ \\ ${ }^{1}$ Neurocognition Lab, Knowledge Media Research Center, Tuebingen, Germany \\ ${ }^{2}$ Department of Psychology, University of Tuebingen, Germany \\ ${ }^{3}$ Section Neuropsychology, Department of Neurology, University Hospital Aachen, RWTH Aachen University, Aachen, Germany \\ ${ }^{4}$ Center for MR-Research, University Children's Hospital Zurich, Zurich, Switzerland \\ *Correspondence: korbinian.moeller@uni-tuebingen.de
}

Edited and reviewed by:

Natasha Kirkham, Cornell University, USA

Keywords: numerical development, approximate number system, developmental dyscalculia, mathematics learning disability, spatial-numerical association, language development

Living at the beginning of the 21 st century requires being numerate because numerical abilities are not only essential for life prospects of individuals but also for economic interests of postindustrial knowledge societies (e.g., Butterworth et al., 2011). In recent years, numerical development has gained increasing research interest. Following this trend, we invited empirical and theoretical contributions for a Research Topic on Numerical development-from cognitive functions to neural underpinnings. We are grateful to all authors for their high-quality contributions, the reviewers for their constructive comments and suggestions in the interactive peer-review, and the publisher's editorial team for their excellent support.

The different contributions nicely illustrate that the construct numerical development does not denote a unitary, clearly circumscribed, and comprehensive entity. Instead, the empirical, review, opinion, and commentary articles clearly suggest that it is important to consider different empirical and theoretical perspectives evaluating cross-domain (e.g., language or spatial abilities) but also domain-specific [e.g., basic numerical competencies, approximate number system (ANS), spatial-numerical associations (SNA)] determinants of and influences on typical but also atypical numerical development.

A first set of studies investigated cross-domain as well as domain-specific influences on typical numerical development. With respect to cross-domain influences LeFevre et al. (2013) showed a reliable impact of children's spatial abilities on numerical skills. Additionally, Durkin et al. (2013) observed that language ability is a unique predictor of actual and future numerical achievement. Getting closer to the domain of numerical cognition, Lafay et al. (2013) found that finger counting may be useful but not necessary to develop accurate symbolic numerical competencies. As regards basic numerical precursor competencies, two studies investigated the influence of the ANS on numerical development. Mejias and Schiltz (2013) suggest that the ANS may be targeted by educational strategies as it seems to be associated with socio-economic status. Lonnemann et al. (2013) observed that children's addition performance is associated with different markers of the ANS during development. For secondary school children, Huber et al. (2013) found the relation of multiplication and division to be stronger for easier problems and more skilled (i.e., higher grade) students. Moreover, two fMRI studies investigated neural correlates of numerical development. Mussolin et al. (2013) observed differential developments of the contributions of the right and left intraparietal sulcus (IPS) to magnitude comparison over age, while Gullick and Wolford (2013) found a fronto-parietal shift of activation with age in general, but also specific effects on the lateralization of IPS involvement for processing negative numbers. Finally, Lambrechts et al. (2013) observed that processing the continuous quantities time and space seems resilient to healthy aging similar to numerosity.

With a particular focus on the determinants of atypical numerical processing in mathematics learning disability (MLD) or developmental dyscalculia (DD), Mazzocco et al. (2013) showed that specific basic whole number misconceptions reliably predict atypical performance on Grade 8 arithmetic tests. Furthermore, Chu et al. (2013) found that even though inacuity of the ANS is a reliable predictor of risk for MLD it may not be its primary source. Nevertheless, Landerl (2013) evaluated the influences of other basic numerical competencies on numerical development and observed that children with DD exhibited specific impairments. Importantly, however, Haase et al. (2014) concluded that subtypes of MLD may not only be associated with content-related deficits but also more general impairments of information processing should be considered. In line with this view, Van Viersen et al. (2013) suggested that evaluating eyefixation behavior may provide interesting new insights into the mechanisms underlying DD. In their Opinion, Kaufmann et al. (2013) argue that MLD/DD is a heterogeneous disorder resulting from individual differences in development or function at neuroanatomical, neuropsychological, behavioral, and interactional levels. Finally, Käser et al. (2013) described the development and first successful evaluation of a multimodal and adaptive computer-based training program for children with DD.

Another set of studies investigated interactions in the processing of numbers and space. With respect to SNA, Knops et al. (2013) observed a reversed operational momentum (OM) effect in children with their degree of attentional control predicting the propensity to exhibit the OM effect. Kucian et al. (2013) commented that the left-right associations underlying the $\mathrm{OM}$ effect may dependent on development, reflecting an interaction of 
visuo-spatial and attentional processes with number related skills which might account for the non-observation of an OM effect in children (with DD). Moreover, Link et al. (2014) observed that unbounded number line estimation may be a valuable tool for assessing primary school children's spatial representation of number magnitude in an unbiased manner. Goldman et al. (2013) argued that the development of an analog comparison process and the specific processing of end stimuli contribute to the emergence of the mental number line. In their review, Patro et al. (2014) suggested a taxonomy for the classification of SNA from infancy to late preschool years. On the other hand, another two studies addressed direct interactions between the processing of numerical and physical magnitude as reflected by the size congruity effect (Henik and Tzelgov, 1982). Leibovich et al. (2013) found that numerical and physical magnitudes are represented by different, yet interactive systems. Ben-Shalom et al. (2013) observed that even preschoolers were able to process number magnitude information automatically. Finally, unrelated to space, Gabriel et al. (2013) suggested that conceptual knowledge about fractions and procedural knowledge about how to manipulate them should be distinguished. Faulkenberry (2013) commented that the evaluation of solution strategies might be beneficial to differentiate procedural and conceptual knowledge.

Extending the focus on language influences Imbo et al. (2014) and Klein et al. (2013) specifically investigated influences of number word inversion on numerical development. They found that language, but not working memory capacity, predicted the number of inversion errors and conclude that inversion-related difficulties do not fade over time, respectively. Lopes-Silva et al. (2014) observed the more basic perceptual phonemic awareness to predict number transcoding reliably, whereas magnitude processing and working memory did not.

As documented by this broad range of studies dealing with different aspects of numerical development-from behavioral performance to underlying neural substrates, from cross-sectional to longitudinal evaluations, from healthy to clinical populationsthe current Research Topic brought together the expertise of researchers from different backgrounds and clearly advanced our understanding of numerical development-a topic with both scientific and every-day relevance.

\section{ACKNOWLEDGMENTS}

The current research was supported by the Leibniz-Competition Fund (SAW) providing funding to Elise Klein (SAW-2014-IWM4). Korbinian Moeller is a member of the LEAD Graduate School of the University of Tuebingen funded within the framework of the Excellence Initiative via the German Research Foundation as well as the "Cooperative Research Training Group" of the University of Education, Ludwigsburg, and the University of Tuebingen supported by the Ministry of Science, Research and the Arts in Baden-Württemberg.

\section{REFERENCES}

Ben-Shalom, T., Berger, A., and Henik, A. (2013). My brain knows numbers! an ERP study of preschoolers' numerical knowledge. Front. Psychol. 4:716. doi: 10.3389/fpsyg.2013.00716

Butterworth, B., Varma, S., and Laurillard, D. (2011). Dyscalculia: from brain to education. Science 332, 1049-1053. doi: 10.1126/science.1201536
Chu, F. W., van Marle, K., and Geary, D. C. (2013). Quantitative deficits of preschool children at risk or mathematical learning disability. Front. Psychol. 4:195. doi: 10.3389/fpsyg.2013.00195

Durkin, K., Mok, P. L. H., and Conti-Ramsden, G. (2013). Severity of specific language impairment predicts delayed development in number skills. Front. Psychol. 4:581. doi: 10.3389/fpsyg.2013.00581

Faulkenberry, T. J. (2013). The conceptual/procedural distinction belongs to strategies, not tasks: a comment on Gabriel et al. (2013). Front. Psychol. 4:820. doi: 10.3389/fpsyg.2013.00820

Gabriel, F., Coché, F., Szucs, D., Carette, V., Rey, B., and Content, A. (2013). A componential view of children's difficulties in learning fractions. Front. Psychol. 4:715. doi: 10.3389/fpsyg.2013.00715

Goldman, R., Tzelgov, J., Ben-Shalom, T., and Berger, A. (2013). Two separate processes affect the development of the mental number line. Front. Psychol. 4:317. doi: 10.3389/fpsyg.2013.00317

Gullick, M. M., and Wolford, G. (2013). Understanding less than nothing: children's neural response to negative numbers shifts across age and accuracy. Front. Psychol. 4:584. doi: 10.3389/fpsyg.2013.00584

Haase, V. G., Júlio-Costa, A., Lopes-Silva, J. B., Starling-Alves, I., Antunes, A. M., Pinheiro-Chagas, P., et al. (2014). Contributions from specific and general factors to unique deficits: two cases of mathematics learning difficulties. Front. Psychol. 5:102. doi: 10.3389/fpsyg.2014.00102

Henik, A., and Tzelgov, J. (1982). Is three greater than five: the relation between physical and semantic size in comparison tasks. Mem. Cognit. 10, 389-395.

Huber, S., Fischer, U., Moeller, K., and Nuerk, H.-C. (2013). On the interrelation of multiplication and division in secondary school children. Front. Psychol. 4:740. doi: 10.3389/fpsyg.2013.00740

Imbo, I., Vanden Bulcke, C., De Brauwer, J., and Fias, W. (2014). Sixty-four or four-and-sixty? The influence of language and working memory on children's number transcoding. Front. Psychol. 5:313. doi: 10.3389/fpsyg.2014.00313

Käser, T., Baschera, G.-M., Kohn, J., Kucian, K., Richtmann, V., Grond, U., et al. (2013). Design and evaluation of the computer-based training program Calcularis for enhancing numerical cognition. Front. Psychol. 4:489. doi: 10.3389/fpsyg.2013.00489

Kaufmann, L., Mazzocco, M. M., Dowker, A., von Aster, M., Göbel, S. M., Grabner, R. H., et al. (2013). Dyscalculia from a developmental and differential perspective. Front. Psychol. 4:516. doi: 10.3389/fpsyg.2013.00516

Klein, E., Bahnmueller, J., Mann, A., Pixner, S., Kaufmann, L., Nuerk, H. C., et al. (2013). Language influences on numerical development - inversion effects on multi-digit number processing. Front. Psychol. 4:480. doi: 10.3389/fpsyg.2013.00480

Knops, A., Zitzmann, S., and McCrink, K. (2013). Examining the presence and determinants of operational momentum in childhood. Front. Psychol. 4:325. doi: 10.3389/fpsyg.2013.00325

Kucian, K., Plangger, F., O'Gorman, R., and von Aster, M. (2013). Operational momentum effect in children with and without developmental dyscalculia. Front. Psychol. 4:847. doi: 10.3389/fpsyg.2013.00847

Lafay, A., Thevenot, C., Castel, C., and Fayol, M. (2013). The role of fingers in number processing in young children. Front. Psychol. 4:488. doi 10.3389/fpsyg.2013.00488

Lambrechts, A., Karolis, V., Garcia, S., Obende, J., and Cappelletti, M. (2013). Age does not count: resilience of quantity processing in healthy ageing. Front. Psychol. 4:865. doi: 10.3389/fpsyg.2013.00865

Landerl, K. (2013). Development of numerical processing in children with typical and dyscalculic arithmetic skills - a longitudinal study. Front. Psychol. 4:459. doi: 10.3389/fpsyg.2013.00459

LeFevre, J.-A., Jimenez Lira, C., Sowinski, C., Cankaya, O., Kamawar, D., and Skwarchuk, S.-L. (2013). Charting the role of the number line in mathematical development. Front. Psychol. 4:641. doi: 10.3389/fpsyg.2013.00641

Leibovich, T., Diesendruck, L., Rubinsten, O., and Henik, A. (2013). The importance of being relevant: modulation of magnitude representations. Front. Psychol. 4:369. doi: 10.3389/fpsyg.2013.00369

Link, T., Huber, S., Nuerk, H.-C., and Moeller, K. (2014). Unbounding the mental number line - new evidence on children's spatial representation of numbers. Front. Psychol. 4:1021. doi: 10.3389/fpsyg.2013.01021

Lonnemann, J., Linkersdörfer, J., Hasselhorn, M., and Lindberg, S. (2013). Developmental changes in the association between approximate number representations and addition skills in elementary school children. Front. Psychol. 4:783. doi: 10.3389/fpsyg.2013.00783 
Lopes-Silva, J. B., Moura, R., Júlio-Costa, A., Haase, V. G., and Wood, G. (2014). Phonemic awareness as a pathway to number transcoding. Front. Psychol. 5:13. doi: 10.3389/fpsyg.2014.00013

Mazzocco, M. M. M., Murphy, M. M., Brown, E. C., Rinne, L., and Herold, K. H. (2013). Persistent consequences of atypical early number concepts. Front. Psychol. 4:486. doi: 10.3389/fpsyg.2013.00486

Mejias, S., and Schiltz, C. (2013). Estimation abilities of large numerosities in Kindergartners. Front. Psychol. 4:518. doi: 10.3389/fpsyg.2013.00518

Mussolin, C., Noël, M.-P., Pesenti, M., Grandin, C., and De Volder, A. G. (2013). Neural correlates of the numerical distance effect in children. Front. Psychol. 4:663. doi: 10.3389/fpsyg.2013.00663

Patro, K., Nuerk, H.-C., Cress, U., and Haman, M. (2014). How number-space relationships are assessed before formal schooling: a taxonomy proposal. Front. Psychol. 5:419. doi: 10.3389/fpsyg.2014.00419

Van Viersen, S., Slot, E. M., Kroesbergen, E. H., van't Noordende, J. E., and Leseman, P. P. M. (2013). The added value of eye-tracking in diagnosing dyscalculia: a case study. Front. Psychol. 4:679. doi: 10.3389/fpsyg.2013.00679
Conflict of Interest Statement: The authors declare that the research was conducted in the absence of any commercial or financial relationships that could be construed as a potential conflict of interest.

Received: 02 September 2014; accepted: 02 September 2014; published online: 19 September 2014.

Citation: Moeller K, Klein E, Kucian K and Willmes K (2014) Numerical development-from cognitive functions to neural underpinnings. Front. Psychol. 5:1047. doi: 10.3389/fpsyg.2014.01047

This article was submitted to Developmental Psychology, a section of the journal Frontiers in Psychology.

Copyright (c) 2014 Moeller, Klein, Kucian and Willmes. This is an open-access article distributed under the terms of the Creative Commons Attribution License (CC BY). The use, distribution or reproduction in other forums is permitted, provided the original author(s) or licensor are credited and that the original publication in this journal is cited, in accordance with accepted academic practice. No use, distribution or reproduction is permitted which does not comply with these terms. 